\title{
Plant growth functions and possible spatial and temporal scaling errors in models of herbivory
}

\author{
A. J. Parsons*, S. Schwinning† and P. Carrère $\ddagger$ \\ *AgResearch Grasslands, Palmerston North, New Zealand, †Department of Biology, University of Utah, \\ Salt Lake City, UT 84II2, USA, and ‡INRA, Unité d'agronomie, Clermont-Ferrand, Cedex 2, France
}

\begin{abstract}
Recent studies have provided detail of the mechanisms by which plants and animals interact, but attempts to apply this knowledge to understand function at the scale of whole fields or grazed ecosystems can be fraught with difficulties. Faced with a plethora of detail, and yet demands to make models more comprehensive, modellers face pressure to revert to simplified accounts for what are assumed to be well-established biological phenomena, for example, for describing plant growth and intake, but this raises the risk that important insights may be lost, or that the analyses may face errors of scaling.

The predictions of a previously described spatial model are compared with those of a non-spatial rendition of the same model to identify the differences in predictions and the sources of these differences. In particular, the use of the conventional empirical growth functions and their interaction with temporal and spatial scaling errors are examined. The comparison exposed how substantial errors could be made in predicting yield and stability under grazing. It is proposed that such errors might be avoided by ensuring that the functional responses used capture the insights of more detailed studies, and by recognizing the difficulties of scaling-up from the level of processes to the field scale and beyond.
\end{abstract}

Keywords: herbivory, spatial, scaling, heterogeneity, grazing, model

\section{Introduction}

Mathematical models of herbivory (grazing) can be valuable tools both for (i) gaining greater insight into the

Correspondence to: A. J. Parsons, AgResearch Grasslands, Private Bag 11008, Palmerston North, New Zealand. E-mail: parsonst@agresearch.cri.nz

Received 22 October 1999; revised 10 May 2000 function and sustainability of natural and managed grazed ecosystems, and (ii) increasing the quality of decision support systems (DSS) aimed at improving or sustaining the efficiency of agricultural land use. There is no shortage of detailed information on which these models can be based. There has been substantial progress in elucidating the mechanisms by which grazing animals respond to vegetation state (see reviews by Laca and Demment, 1996; Ungar, 1996) and of how vegetation growth responds to grazing (reviews by Richards, 1993; Parsons and Chapman, 1999). The principles of the overall trade-off between growth and utilization, and the concepts of stability and sustainability of grasslands are well established (Noy-Meir, 1975; Johnson and Parsons, 1985; Tainton et al., 1996), but this is all predominantly in the context of what are assumed to be uniform, homogeneous pastures. This is despite the fact that grazing is widely recognized as a process that generates heterogeneity in pastures (Coughenour, 1991), and that some forms of heterogeneity are important as sources of poor utilization and pasture degradation.

Recently, there has been an increasing interest in understanding spatial and temporal heterogeneity and its origin and consequences to the function, yield and stability of ecosystems (Silander and Pacala, 1990; Coughenour, 1991; Tilman, 1994). This has encouraged the development of spatial models of grazing and plant/ animal interactions (e.g. Laca and Demment, 1991; Grunbaum, 1998; Schwinning and Parsons, 1996a, b; 1999). Indeed, many authors comment on the need to study grazing at a wide range of spatial and temporal scales (Senft et al., 1987; Laca and Ortega, 1995).

Recasting long established concepts of grazing, into spatial models, and making use of the greatly increased detail in understanding grazing, raises a number of problems. The considerable progress in understanding behaviour and intake in grazing animals has been the result of making studies at the bite scale (see Penning, 1986; Demment et al., 1987; Illius and Gordon, 1987; Ungar and Noy-Meir et al., 1988; Spalinger and Hobbs, 1992; Parsons et al., 1994; Penning et al., 1995). At this scale defoliation is seen as a series of discrete (biting) 
events. This progress has been complemented by advances in understanding the physiological response of plant growth to various defoliation regimes (Parsons and Penning, 1988; Richards, 1993; Parsons et al., 1988). This knowledge could be applied at a range of scales, but in grazing models, plant growth is often conceived at the field scale, with growth in the presence of grazing animals seen as a continuous process (e.g. Johnson and Parsons, 1985; Thornley, 1999; and see review by Woodward, 1998). There is therefore a potential imbalance in both spatial and temporal scales. It has long been recognized that errors can arise when attempting to relate observations and phenomena at one scale to those at another scale (Wiens, 1989; Brown and Allen, 1989; Marriott and Carrere, 1998). A further concern is that there is always pressure to reduce the level of detail in models to the minimum in areas where it is perceived the biology is long established. In grazing models, there is pressure to revert from physiological treatments of plant growth to simple growth functions. This, we shall see, potentially compounds the scaling errors.

Schwinning and Parsons (1999) developed a spatial model, where both grazing and plant growth were combined as discrete processes and at the bite scale, to investigate whether adding spatial detail in both plants and animals might lead to new insights into the yield and stability of grazing systems, and into the role of heterogeneity in reducing utilization. In that paper (and see Parsons et al., 1999) the authors compared how some simple but fundamentally contrasting foraging strategies affected system function. However, all comparisons were made using the discrete spatial modelling approach. In the present paper, the predictions of one example of that spatial model are compared with those of a non-spatial rendition of the same model in an attempt to identify any pitfalls in interpretation and the source of differences in the predictions of non-spatial and spatial approaches. Notably we explore the possibility of difficulties in using conventional empirical growth functions and the way this interacts with spatial and temporal scaling errors.

\section{Plant growth functions and the modelling of plant growth}

Increases in the mass (leaf area, height or density) of the grass crop have long been represented by a simple logistic growth curve (see reviews by Thornley and Johnson, 1990; Birch, 1999). This form of curve has been empirically derived from instances where the sward is regrowing from a low initial state, such as from seedlings or during regrowth after defoliation to a low residual leaf area. In these instances the logistic equation, and more recent modifications of it (Cacho, 1993; Birch, 1999), can adequately describe the net accumulation of biomass. However, these functions do not adequately predict plant growth when biomass is less severely reduced at the time of harvest.

It has long been established, both empirically and theoretically, that in swards of grassland species with a programmed turnover of leaves, growth after lenient defoliation does not retrace the corresponding portion of the growth curve measured after severe defoliation [e.g. see Parsons et al. (1988) and references therein]. After lenient defoliation, net growth rates are lower at a given intermediate biomass than when vegetation is regrowing through that same biomass after severe defoliation (see Figure 1). The difference in growth rates at the same intermediate biomass is due to the

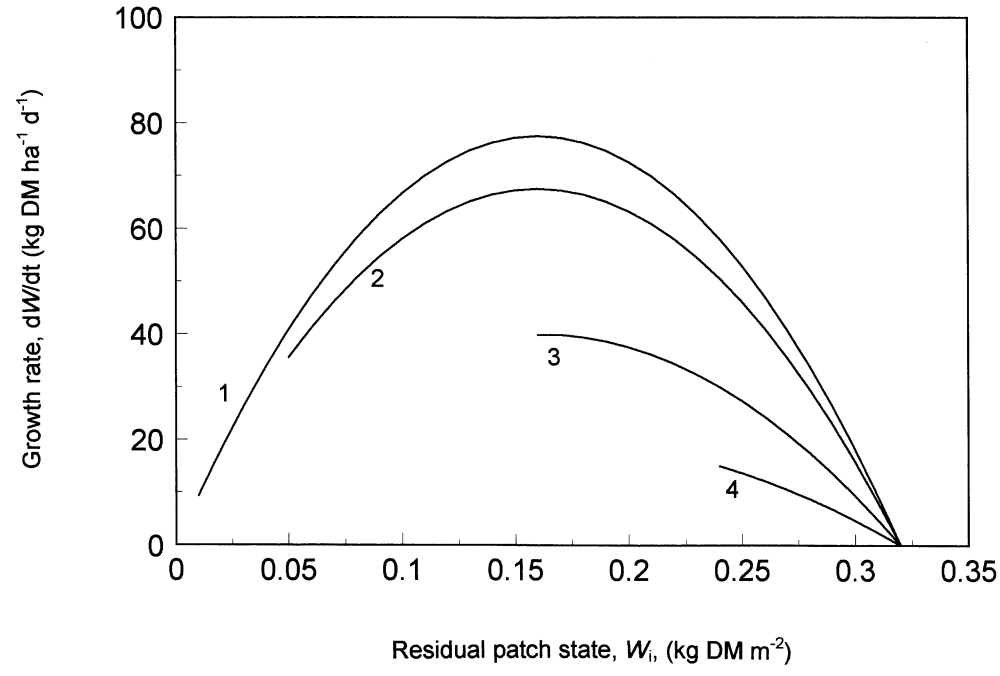

Figure I Changes in the instantaneous growth rate, $d W / d t$, during regrowth after severe defoliation (line I) and after increasingly lenient defoliations (higher residual biomass, $W_{i}$, lines 2, 3 and 4) as described by a growth function (Eqn I) modified to consider the sensitivity of regrowth to residual vegetation state. For comparison of these phenomena with a physiological and age-structured model of grass growth see Parsons et al. (1988). 
different age structures of the population of leaves present (Parsons et al., 1988; Schwinning and Parsons, 1999).

These phenomena cannot be represented by a single conventional logistic growth curve, though they are readily apparent in physiological models of plant growth which formulate the flux of mass through a number of leaf age-categories, or 'compartments' (e.g. Johnson and Parsons, 1985; Thornley, 1999) or which use differential-delay equations (e.g. Woodward and Wake, 1994). Nevertheless, despite the availability of these, the basic logistic equation has remained widely used, and its use in models may increase again due to demand for simplicity in some areas to make room for more detail elsewhere.

\section{A modified logistic equation}

It is not the aim of this paper to advocate a particular growth function, but to illustrate some of the problems of omitting the phenomena described above, we compare a conventional logistic equation with one that has been modified to demonstrate the sensitivity of the response of plant growth to residual pasture state. In Schwinning and Parsons (1999) an example of a modification to the conventional logistic equation was introduced to generate these phenomena in a non-compartmental model by adding a simple factor $\left(1-W_{\mathrm{i}} / W_{\max }\right)$ that modifies the growth rate according to the value of $W_{\mathrm{i}}$, the residual (initial) sward state immediately after defoliation:

$$
\mathrm{d} W / \mathrm{d} t=\mu W\left(1-W_{\mathrm{i}} / W_{\max }\right)\left(1-W / W_{\max }\right) .
$$

As in the logistic equation, $\mu$ is a parameter describing the maximum specific growth rate [e.g. $0 \cdot 1 \mathrm{~kg}$ dry matter (DM) $\left.\mathrm{kg}^{-1} \mathrm{~d}^{-1}\right]$, and $W_{\max }$ is the maximum sward biomass (e.g. $0.32 \mathrm{~kg} \mathrm{DM} \mathrm{m}^{-2}$ ). For any given value of $W_{\mathrm{i}}$, this function can be integrated just like the logistic equation (Schwinning and Parsons, 1999). The function expresses sensitivity to defoliation severity in the following way: When $W_{\mathrm{i}} \rightarrow 0$ (low initial conditions for regrowth), this equation is indistinguishable from the conventional logistic. Under all other conditions, the rate of regrowth is diminished by a factor proportional to the relative difference between a fully grown sward and the sward just after defoliation, consistent with physiological models and observation (see Figure 1).

Two basic reasons are proposed for why such an apparently simple modification is necessary, over and above getting a better match to observed phenomena. The first relates to possible difficulties in interpretation that can arise from reverting to empirical growth functions, rather than process-based accounts, and regarding what is the optimal defoliation regime. The second relates to issues of spatial and temporal scaling that become apparent when comparing spatial models of grazing based at the bite scale, with non-spatial models based at the field scale, and which interact with the choice of growth function.

\section{Difficulties in interpretation}

One advantage of using simplified growth functions in the grazing context is that we can solve them to describe the theoretical optimal solutions for maximum sustainable yield for all possible defoliation regimes. To do this, for each possible residual (initial) state, $W_{\mathrm{i}}$, we can identify an optimal timing of harvest during the subsequent regrowth as being the time, $\mathrm{t}^{*}$, when the average growth rate, here $\left(W-W_{\mathrm{i}}\right) / \mathrm{t}$, is maximum (Parsons et al., 1988 and see Morley, 1968). Identifying an average growth rate as a currency for optimization is consistent with the marginal value theorem (MVT) of optimal patch exploitation in foraging theory (Charnov, 1976).

The effect of residual sward state on the maximum sustainable yield and the defoliation interval necessary to achieve it in each case (the series of local optimal solutions) is described for the new growth function by the broken line in Figure 2. In this example (see Schwinning and Parsons, 1999), this approach identifies a theoretical global optimal solution as occurring when $W_{\mathrm{i}}=0.049 \mathrm{~kg} \mathrm{~m}^{-2}$ and, after a defoliation interval, $\mathrm{t}^{*}=28 \cdot 2 \mathrm{~d}$. This combination provides a maximum sustainable yield of $58 \mathrm{~kg} \mathrm{ha}^{-1} \mathrm{~d}^{-1}$.

The conclusion, here, that 'infrequent severe' defoliation yields more than 'frequent lenient' defoliation, is consistent with the consensus that has emerged from the literature, despite considerable initial controversy (e.g. see Brougham, 1956; Anslow, 1967; Brougham and Glenday, 1967; and reviews by Parsons, 1988; 1994). There are certainly additional factors, such as changes in sward structure, that also determine the merits of contrasting defoliation regimes, but the critical issue is that the phenomena shown in Figure 2 are consistent with widespread agronomic observation.

By contrast, the possible difficulties in interpretation that arise when using a conventional logistic growth function, and hence the proposed need to modify the logistic, can be seen from the solid lines in Figure 2a and $b$, where the same procedure has been used to predict the optimal solutions from a conventional logistic (all same parameter values). In this case the analysis implies that the maximum sustainable yield would be achieved when the sward is defoliated leniently (to half maximum biomass), and with negligible defoliation interval, indeed continuously. Hence using a logistic growth curve that is empirically based on data from infrequent severe defoliation can ironically lead to the interpretation that greatest yields would be achieved using continuous lenient grazing. 


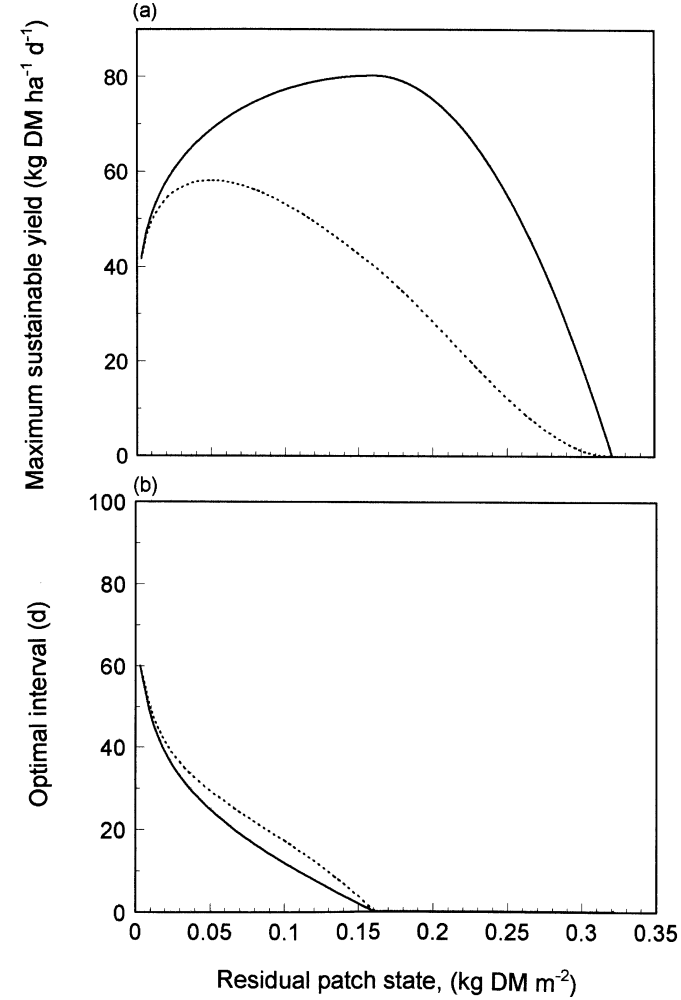

Figure 2 The optimal solutions for harvesting grass predicted assuming it regrows either according to a conventional logistic (solid lines) or the new growth function (dotted lines) where regrowth is sensitive to the residual vegetation state. The lines show the effect of residual patch state on (a) the maximum sustainable yield (maximum average growth rate) that may be achieved, and (b) the defoliation interval required to achieve this.

\section{Spatial issues in models of herbivory}

In the following sections we compare the performance and predictions of a 'spatial' model of grazing with a 'non-spatial' version of the same model as a means through which a number of issues of spatial and temporal scaling are identified and to test the sensitivity of the model predictions to each of these. Notably we investigate how scaling interacts with the choice of growth function.

The model has been described in detail by Schwinning and Parsons (1999). Here, it is only necessary to consider the nature of the two particular cases that will be used to illustrate a general comparison of a nonspatial as opposed to a spatial modelling approach. The fundamental differences between these variants of the same model are portrayed diagramatically in Figure 3, and the constraints that the alternative approaches impose on the methods used for calculating intake and plant growth are apparent in Table 1 .

In our spatial approach we model grazing as a discrete process, recognizing that at the bite scale plants always experience a sequence of near instantaneous defoliations separated by uninterrupted periods of regrowth (the intervals between defoliations). The sward is conceived as a huge array of bite-sized patches. Intake is calculated mechanistically from bite mass, assuming a fractional bite depth, ' $f$ ', of either 1.0 or 0.5 of the standing vegetation above an ungrazeable horizon, at each bite (see Ungar et al., 1991; Laca et al., 1992; Edwards et al., 1996). The amount removed is subtracted from each patch in question (and so only from those patches actually grazed). Plant growth is also modelled at the bite scale, each and every patch growing between defoliations according to the growth function in ques-

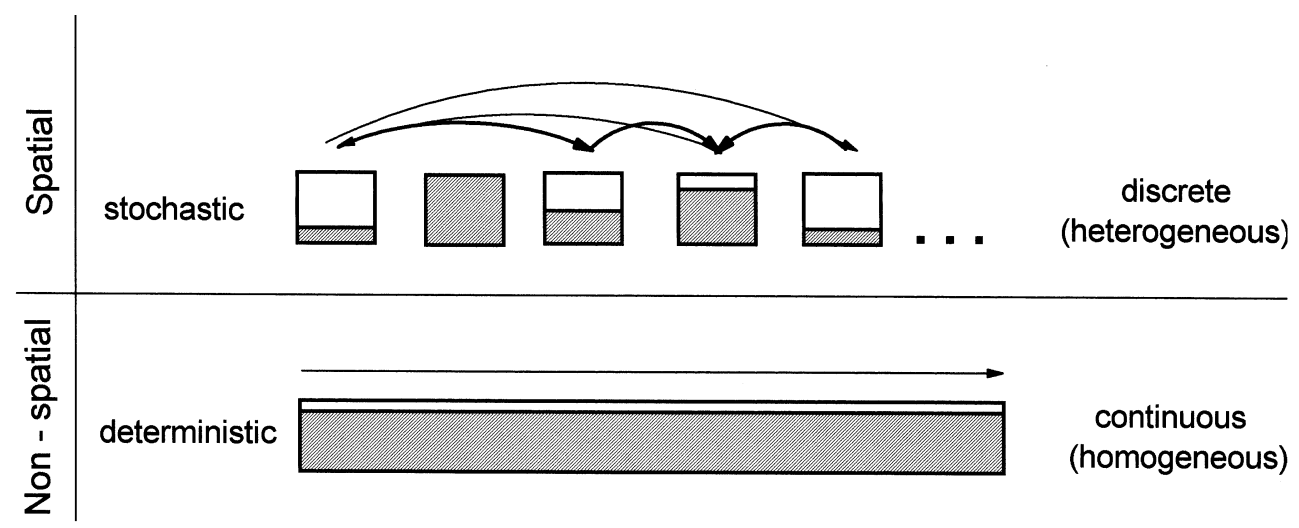

Figure 3 Diagram to show the fundamental difference between the spatial and non-spatial approaches used here. In the spatial model animals graze, in this example spatially and temporally at random, from a huge array of bite-sized patches in a series of discrete defoliations, creating heterogeneity and giving variance (stochasticity) in patch state and defoliation interval. In the non-spatial model animals must be assumed to 'plane off' their total daily intake from across the entire area each day, and so graze as a continuous, homogeneous and deterministic process. 
Table I The fundamental differences between the spatial and non-spatial variants of the grazing model in the way intake and plant growth are calculated, and which lead to difficulties in scaling.

\begin{tabular}{|c|c|c|c|c|}
\hline & \multicolumn{2}{|r|}{ Animal } & \multicolumn{2}{|c|}{ Vegetation } \\
\hline & Bite mass & Daily intake & Defoliation & Growth \\
\hline Spatial & $\begin{array}{l}\text { Each bite depends } \\
\text { on state of } \\
\text { patch eaten }\end{array}$ & $\begin{array}{l}\text { Sum bites till animal satiated } \\
\text { or maximum grazing time } \\
\text { reached }\end{array}$ & $\begin{array}{l}\text { Subtract each bite mass } \\
\text { from each patch on day } \\
\text { of bite }\end{array}$ & $\begin{array}{l}\text { Regrow each patch (eaten } \\
\text { or not) individually each } \\
\text { day }\end{array}$ \\
\hline Non-spatial & $\begin{array}{l}\text { All bites depend } \\
\text { on mean } \\
\text { vegetation state }\end{array}$ & $\begin{array}{l}\text { Sum bites till animal satiated } \\
\text { or maximum grazing time } \\
\text { reached }\end{array}$ & $\begin{array}{l}\text { Subtract daily intake from } \\
\text { mean vegetation state } \\
\text { each day }\end{array}$ & $\begin{array}{l}\text { Regrow mean state of } \\
\text { vegetation each day }\end{array}$ \\
\hline
\end{tabular}

tion, which for the new growth function includes a 'memory' of the initial patch state. In the present paper we consider just one example of a spatial foraging 'strategy' by the animals, the simplest case, where animals distribute their bites spatially and temporally at random (a Poisson process, or a random walk). As a result the animals eat from a wide range of patch sizes, and so have variable bite masses. There is variance (heterogeneity) about the mean residual patch states and about the mean defoliation interval. This arises due to uncertainty as to when, and even if, particular patches are defoliated. Other contrasting and arguably more realistic foraging and patch selection processes are considered elsewhere (Schwinning and Parsons, 1999; Parsons et al., 2000).

For comparison we present a more conventional nonspatial variant of the same model (see Figure 3). In the non-spatial example, intake is again derived mechanistically from bite mass (i.e. at the bite scale) and assuming an identical fractional bite depth. The first critical difference is that, in the non-spatial model, bite mass can only be derived from a single value, the 'mean' vegetation state (see Table 1). This does not seem unreasonable, but this done, there is a second critical difference and source of some concern. There is now a dilemma as to how to subtract the calculated daily intake from the vegetation state. In a non-spatial model we can see little option but to subtract the daily intake from the 'mean' vegetation state each day. Likewise, plant growth is calculated each day based on the mean vegetation state, no other descriptor of the vegetation is available. In this way plant-animal interactions are modelled as a homogeneous and continuous process. In the non-spatial approach, of course, no spatial foraging strategy can be considered.

In all cases, the model was run using either the new growth function advocated here, or using the conventional logistic. At all times the comparison was made using identical parameters, though results are shown for the two fractional bite depths (' $f^{\prime}=1.0$ or 0.5 ) and for a wide range of stock densities.

\section{Sources of differences in model predictions}

The different approaches, non-spatial vs. spatial, give substantially different predictions, see Figures 4 and 5 and as described below, where we use a variety of runs of the models in an attempt to isolate the source of these differences, systematically.

Overall, modelling grazing as a non-spatial (homogeneous, continuous) process can be seen to overestimate yield and exaggerate instability compared with modelling it as a spatial (discrete, stochastic) process. The difference in prediction is largest when using a conventional logistic growth function combined with a large bite depth. We propose that there are four major sources of difference between the predictions of the non-spatial and spatial models. These are: (i) scaling 'error', (ii) inappropriate growth function, (iii) sampling 'errors', and (iv) determinism.

\section{i. Scaling error}

Much of the difference between the predictions of the non-spatial and spatial models (solid lines vs. dotted lines in Figures 4 and 5 ) is due to a spatial scaling error, albeit one which interacts with the form of growth function that is used. The error arises because, in the spatial versions of the model, and we propose in reality, the defoliation fraction (bite depth, $f$ ) is removed explicitly from each patch that is grazed, and so each defoliation is relatively severe and patches regrow from a relatively low residual state. The problem is that during any one day, at any stock density that would lead to an equilibrium between vegetation and animal intake, animals cannot sustainably graze across the entire grazeable area, their biting will be confined to a relatively small proportion of the patches in the 'field'. It has been both measured, and calculated (see Wade, 1991; Parsons and Chapman, 1998) that at a productive equilibrium, only some $2-5 \%$ of the total grazeable area is defoliated in one day. In the non-spatial approach, averaging the amount that is removed per day, in effect 
over the total area, predicts far more lenient defoliation (approximately, e.g. 1/20 what it should be) and so higher mean residual patch states than is realistic. Repeating this procedure to calculate intake each day implies very short ( $1-\mathrm{d})$ defoliation intervals. An error therefore arises in predicting yield and stability when using growth functions, like the conventional logistic, that have a maximum instantaneous growth rate at a high (half maximum) sward state, and so which predict substantial benefits to the incorrectly estimated lenient grazing of patches. In summary, modelling grazing as a non-spatial (homogeneous and continuous) process, and using a logistic growth function, potentially reintroduces the controversy over the relative merits of frequent lenient and infrequent severe defoliation.

\section{ii. Interaction with inappropriate growth function}

The impact of growth functions per se on the prediction of yield and stability can be seen by comparing the solid lines in Figure $4 \mathrm{a}$ with the same solid lines in Figure $4 \mathrm{~b}$. This comparison shows the effect of growth function per se in a non-spatial model. Comparing the dotted lines in Figure $4 \mathrm{a}$ with those in Figure $4 \mathrm{~b}$, shows the effect of growth function per se in a spatial model. Likewise, the impact of the growth functions is compared at a different bite depth in Figure $5 \mathrm{a}$ and $\mathrm{b}$.

In non-spatial models, the logistic growth function overestimates stock carrying capacity (SCC) relative to the new growth function. This is to be expected because non-spatial models at all times here incur the scaling error and so underestimate the severity of grazing. The logistic predicts high productivity, while the new growth function predicts much reduced productivity under the miscalculated lenient defoliation. The same order of difference is seen at both fractional bite depths as, in effect, bite depth is spurious, being used to calculate bite mass but not the severity of defoliation.

In spatial models, growth is taking place from more realistic residual patch states, ones consistent with the biting parameters, and over more realistic intervals. Here, the logistic gives results similar to the new growth function when defoliation is severe, as both functions predict similar growth rates from a low residual state. But where defoliation with each bite is relatively more lenient, such as at the more realistic 0.5 fractional bite depth, the logistic again overestimates yield and performance.

Given that the logistic growth curve is quite appropriate for growth from a low initial state, it has been proposed that this form of curve might still be appropriate under grazing in situations where each bite removes a large proportion of the standing vegetation. While this is certainly true at the scale of individual bite-sized patches, it is ironically in this situation, when bite fraction approaches $1 \cdot 0$, that using the logistic gives the greatest 'errors' when attempting to approximate growth in a non-spatial model at the field scale (see Figure 4a).

\section{iii. Sampling errors}

In non-spatial models the vegetation is necessarily assumed to be homogeneous (it has a single invariate mean state): in spatial models there is inevitably heterogeneity, as grazing gives rise to a frequency distribution of patch states, from which animals graze and plants regrow. The frequency distribution of patch states in reality, and in the stochastic spatial model, shows great variance and may be skewed (depending on stock density) and may even be bi-modal (Gibb et al., 1989, 1997). It must be considered that 'sampling' errors may be incurred in calculating intake and/or plant growth from a single mean, which in some cases may be unrepresentative of the patches animals graze and may even be far removed from the 'mode'.

To gain some insight into the impact of variance in patch states on the estimates of intake and of plant growth and their impact on the outcome of the plant/ animal interaction, some of the information derived in Figures 4 and 5 is re-plotted in Figure 6 in relation to mean vegetation state. This makes it possible to compare the performance of the system in situations where the mean vegetation state is the same but where, in one case, there is sustained dynamic variance about that mean (as in spatial models), whereas in the other case there is no variance about that mean (as in non-spatial models).

Clearly in Figure 6, variance in patch state has an effect on the prediction of plant growth and so intake per ha. This is seen by comparing the prediction of the spatial models (dotted lines) with that of the non-spatial models (solid lines). Fascinatingly, and perhaps counter-intuitively, the variance in patch states is seen, in Figure $6 \mathrm{~b}$, to have no effect on the prediction of intake per animal.

The reasons for these phenomena are straightforward. First, with respect to plant growth, regrowth is non-linearly related to vegetation state and so averaging growth rates across the variance about the mean patch state is certain to give rise to a different mean growth rate than one calculated from the mean growth rate alone, as is widely recognized. It is equally widely held that the 'functional response' of animals to vegetation state is non-linear, and that intake will also be subject to 'sampling errors'. However, at the bite scale, the response of animals to vegetation state is assumed here (based on the literature) to be linear (Laca et al., 1992), bite mass increasing linearly with vegetation state barring a possible ungrazeable mini- 
(a)

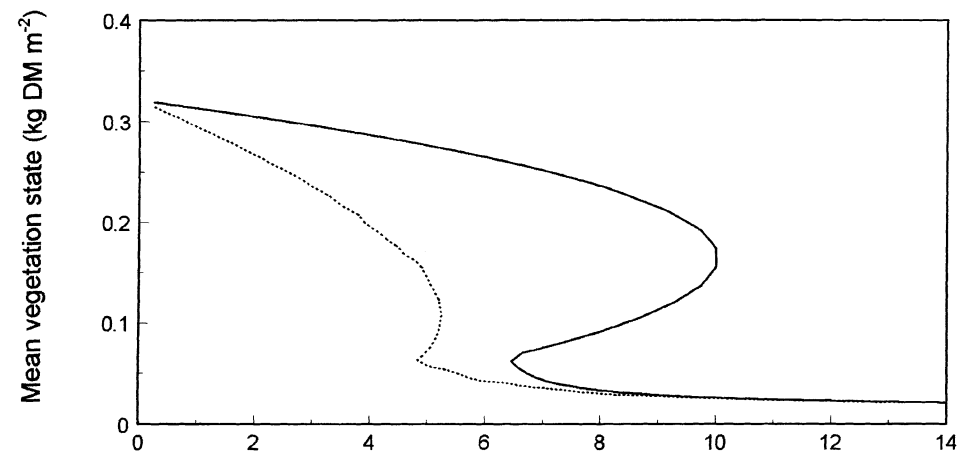

(b)

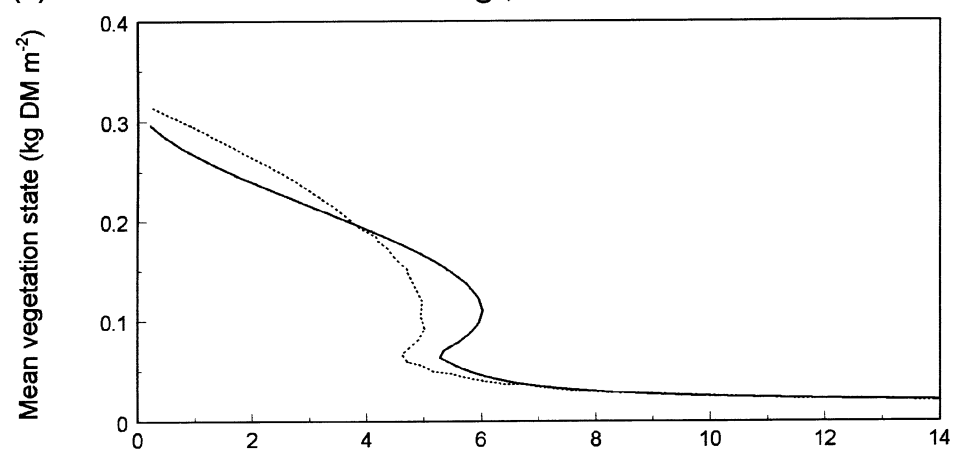

Figure 4 Differences in the predictions (the stable equilibrium solutions) of the non-spatial (solid lines) and spatial (dotted lines) approaches, obtained using either a logistic (a) or the new growth function (newgf) (b). All cases in this figure assume fractional bite depth ' $f$ ' $=1$. See text for analysis of the sources of the differences.

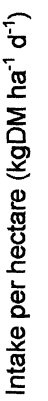

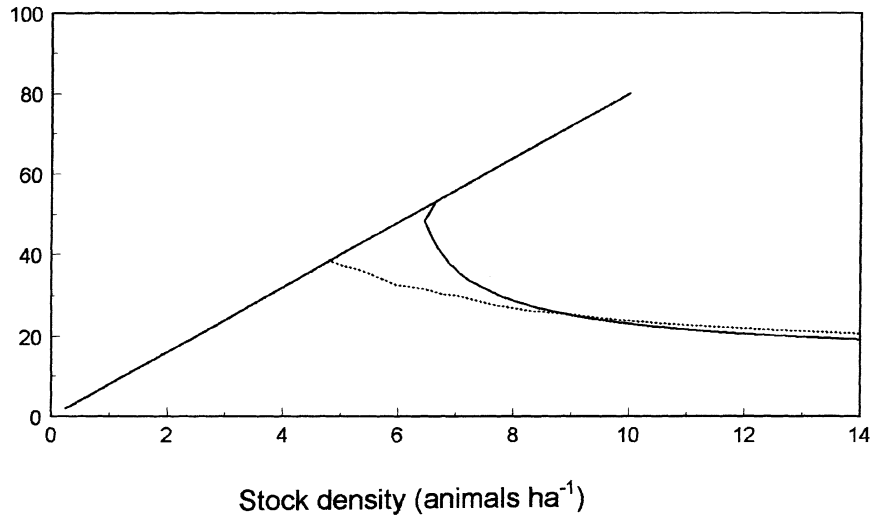

logistic, $\mathrm{f}=1.0$

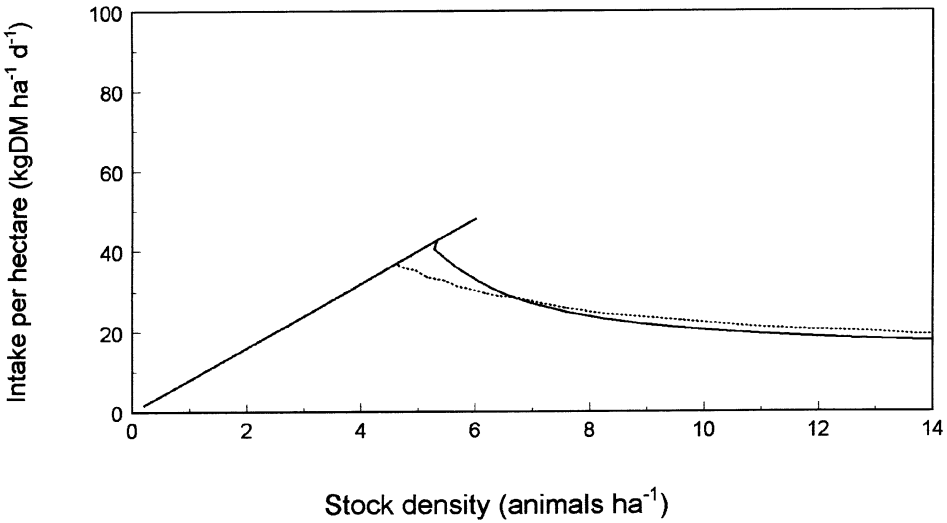


(a)
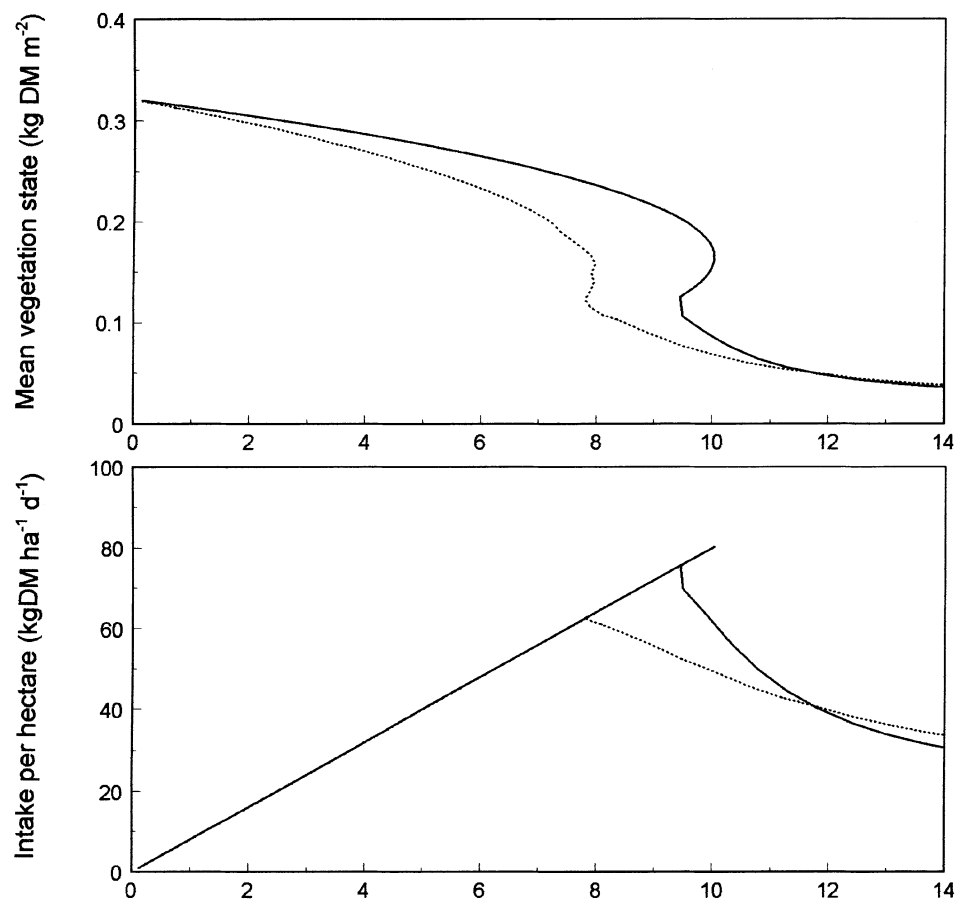

Stock density (animals ha-1)

(b)
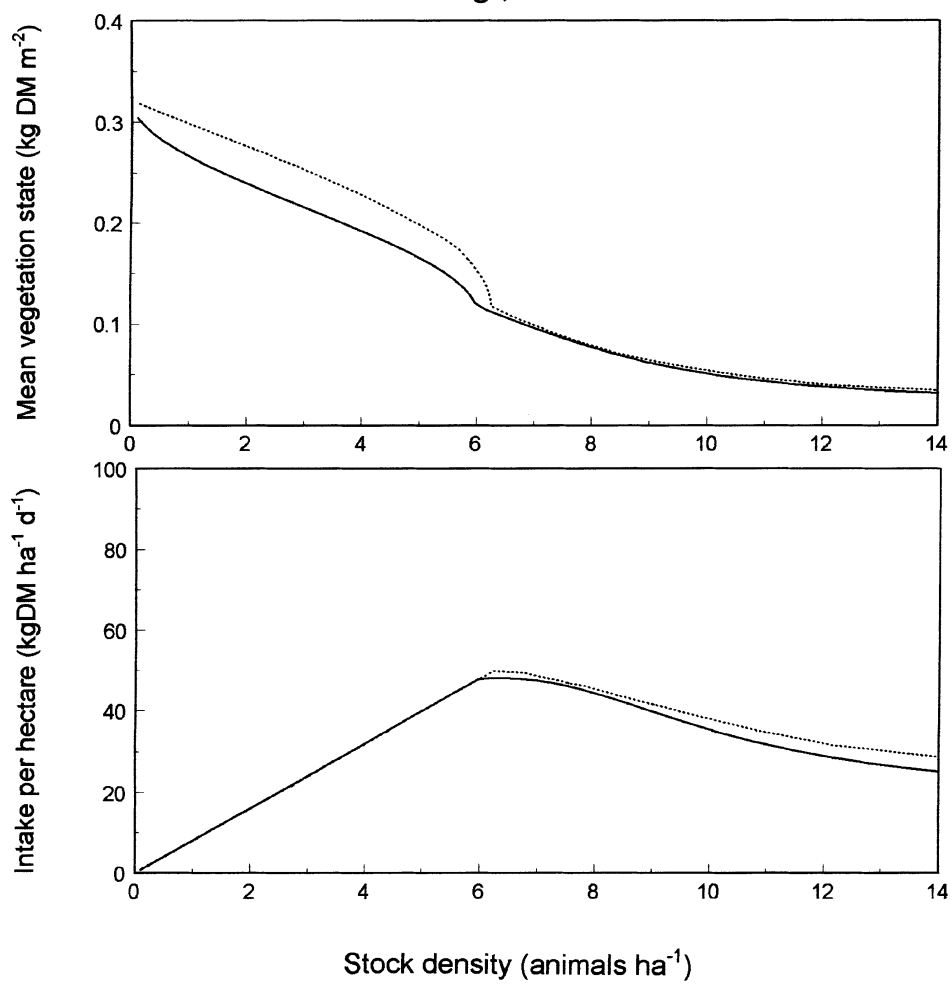

Figure 5 Differences in the predictions (the stable equilibrium solutions) of the non-spatial (solid lines) and spatial (dotted lines) approaches, obtained using either a logistic (a) or the new growth function (newg) (b). All cases in this figure assume fractional bite depth ' $f$ ' $=0 \cdot 5$. See text for analysis of the sources of the differences. 
Figure 6 The effect of variance per se in patch states (see 'sampling errors' in text) on the prediction of intake per ha (a) and per animal (b) is shown by comparing, at the same mean sward state, the solutions where there is no variance in patch states (non-spatial model, solid lines) with those where there is variance in patch states (spatial model, dotted lines and not clearly visible in 'b' as solutions are identical). All runs use the new growth function (Equation I) and a fractional bite depth ' $f$ ' $=0.5$. Also shown (dot-dash line) are the solutions for the same spatial model but where animals graze selectively with a partial rejection of tall patches. (a)

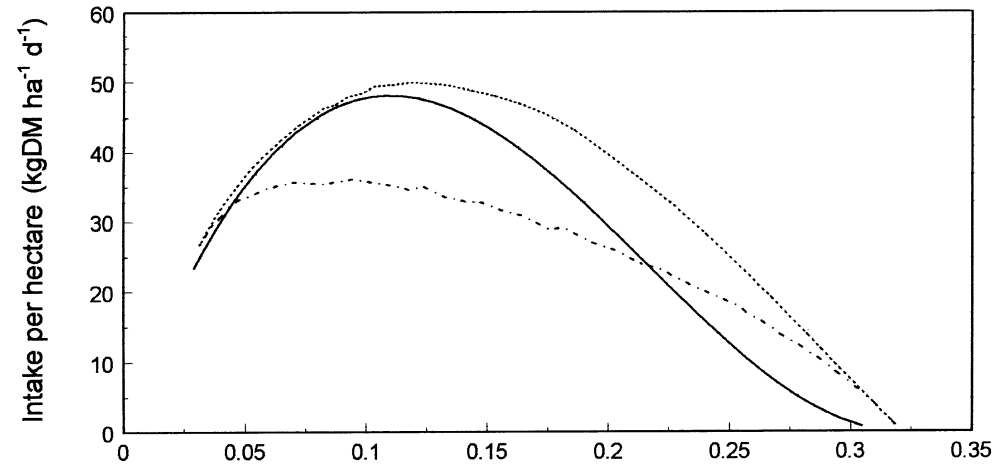

(b)

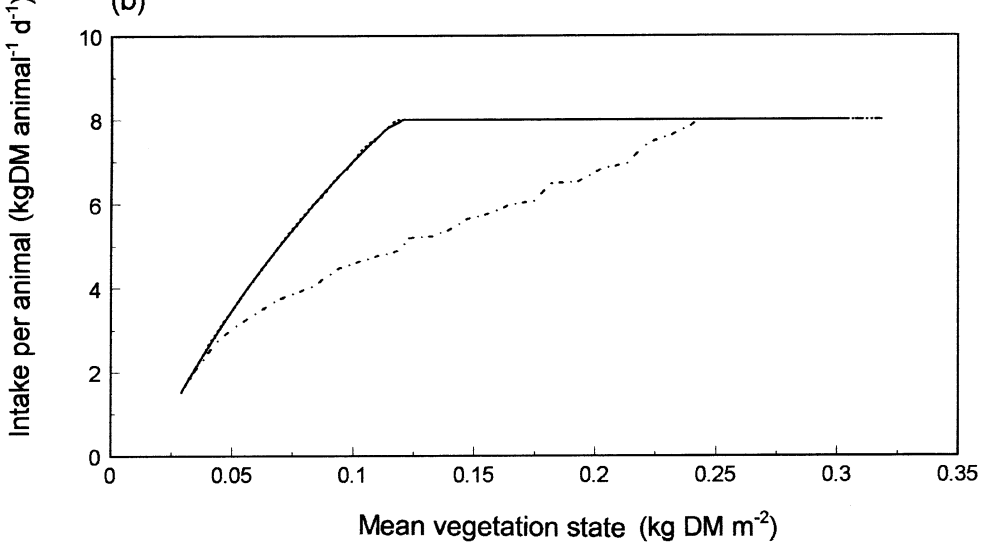

mum vegetation state. Likewise, time taken per bite (both in prehension and mastication) is assumed to increase linearly with vegetation state (see Spalinger and Hobbs, 1992; Parsons et al., 1994). Together these two functions do generate a non-linear, saturating or asymptotic, relationship between instantaneous intake rate and vegetation state. This is due to the fixed time cost associated with prehending bites. Again, here, as in many grazing models, intake per day is constrained either by a maximum daily intake $\left(8 \mathrm{~kg}_{\text {animal }}{ }^{-1} \mathrm{~d}^{-1}\right)$ or by a maximum daily grazing time (48000 s) and this imposes non-linearity in the 'functional response' for intake at the field scale. But during a period of grazing (a bout or a day), the sum of the bite masses and the sum of the grazing times accumulates linearly with vegetation state. Therefore, the variance per se in patch states does not affect the estimate of intake per day.

\section{iv. Determinism}

The level of determinism largely affects the predictions of the stability of the system. In a previous paper (Schwinning and Parsons, 1999) a deterministic example of a spatial model was used to show how this, in itself, increases the tendency for the model to predict discontinuous stability (sensu Noy-Meir, 1975). Schwinning and Parsons (1999) discuss how this implies that the paradigms for grassland management based on earlier, highly deterministic analyses, may overstate the relevance of dual stability. In the present context, all that is added are that some of the predictions of high yield and high SCC, notably in the case of the nonspatial models, depend substantially on there being a high-stable branch of a bi-stable region of the model solutions. In the broadest sense, the solutions of the spatial models pass between the highly contrasting alternative solutions (the bi-stable regions) of the nonspatial models, and this itself means the spatial models predict lower SCC.

\section{Discussion}

Growth functions have long been the focus of studies in the biological sciences and it is not our aim here to advocate a particular new growth function. We present a simple modification of a conventional logistic, purely because it addresses one aspect of plant regrowth, namely the sensitivity to initial conditions, that we 
consider has proved to be important. Residual sward state has become widely used as a practical management tool but sensitivity to this has been overlooked in some recent and widely applied growth functions. Our proposed modification adds a simple factor that could be incorporated directly into conventional functions (including that of Cacho, 1993) to provide highly flexible devices for representing growth. This approach does not substitute for a physiological, or process-based, account for situations where the aim is to explain changes in growth and ecosystem behaviour, but these simplified functions may provide a way to portray growth in practical models (e.g. in decision support software), or in models that are highly complex in other areas, and thereby rationalize plant growth to an acceptable minimum.

It has long been recognized that even continuous grazing is actually a form of discrete 'rotational' defoliation at the bite scale (Hodgson and Ollerenshaw, 1969; Morris, 1969; Clark et al., 1984), but few spatial models of grazing have been produced to take account of this. It has remained unclear whether analyses of the growth response of plants to the mean impact of animals, and of the intake response of animals to the mean sward state, as is implicit in any non-spatial approach, provides an adequate approximation to reality, or whether a spatially explicit account would differ substantially in its predictions of yield and stability. While we have attempted to address this in this paper, it is not the purpose of this paper to criticize any approach to modelling grazing, nor to imply what particular approach or combinations is 'right' or 'wrong', merely to draw attention to possible differences in predictions and interpretation and attempt to locate systematically the source of these.

As a guide only, we summarize in Figure 7, the order of differences in prediction between a 'conventional' approach vs. an example of a bite scale, spatial approach. In Figure 7, we compare the performance of a non-spatial (homogeneous continuous) model, using a logistic growth function and an acceptable intermediate fractional bite depth $(f=0.5)$, with that of a fully spatial (discrete stochastic) bite scale version, using a growth function more responsive to residual vegetation states (as Eqn 1 or a physiological model), and the same $f=0 \cdot 5$. This we propose as most 'realistic'. The difference in prediction is fundamental and important. The non-spatial approach predicts a maximum SCC of ten animals $\mathrm{ha}^{-1}$, and serious management implications for exceeding this (Noy-Meir, 1975 and see Schwinning and Parsons, 1999). The spatial model predicts a maximum SCC of just six animals ha ${ }^{-1}$. But this is not the end of the possible differences.

Spatial models would be justified if they (i) exposed possible differences, and so potential problems, in the predictions and interpretation of non-spatial approaches, as above, but also (ii) if they provided new insights. In this context, spatial models may prove pivotal in increasing our understanding of the origin and consequences of heterogeneity and the role of patch selection in the performance and sustainability of grazing. So far we have described a Null Model for patch selection, by assuming that animals are grazing spatially at random. While there is evidence that this is a valid and realistic foraging strategy (see Edwards, 1994), few will consider this is how animals consistently graze. Selective grazing of patches, notably state-dependent selection, is an important phenomenon of optimal foraging. When we introduce one such aspect of selective grazing (a partial rejection of tall patches), this reduces the predicted SCC from ten to just three animals $\mathrm{ha}^{-1}$ sustained at their maximum intake per animal (see dot-dash line, Figures 6 and 7). Elsewhere (Schwinning and Parsons, 1999; Parsons et al., 2000) we propose how similar grazer preferences may help explain the emergence of deleterious forms of spatial heterogeneity, notably a bimodal distribution of patch states as observed by Gibb et al. (1997), and the associated poor utilization. It is only with spatial models that the consequences of such contrasting foraging strategies, and the impact of the associated spatial heterogeneity, can be explored.

\section{What level of detail is necessary?}

Substantial progress and insights into grazing have long been established using non-spatial models. Spatial models were constructed and compared with nonspatial models, in this paper, predominantly to explore the problems of growth functions interacting with issues of scale. The level of detail required in a model of herbivory depends, of course, on the kind of insight that is sought.

From Figures $4 \mathrm{~b}$ and $5 \mathrm{~b}$ it would appear that $\mathrm{a}$ relatively low level of spatial and physiological detail might be necessary to model grazing, provided that the functional responses themselves adequately capture the insights gained from previous more detailed approaches. The modified growth function, such as physiological age-structured accounts, appears less sensitive than a conventional logistic to the choice of scale, and appears to give good approximations even when the system is modelled as a homogeneous and continuous, non-spatial, process. However, we cannot recommend adopting inconsistencies in scaling even if the outcome is little affected.

Where the aim was to study the stability of the plant-animal interaction spatially, we found that a minimum of 3000 patches had to be modelled, explicitly, to identify the appropriate characteristics of the 
(a)

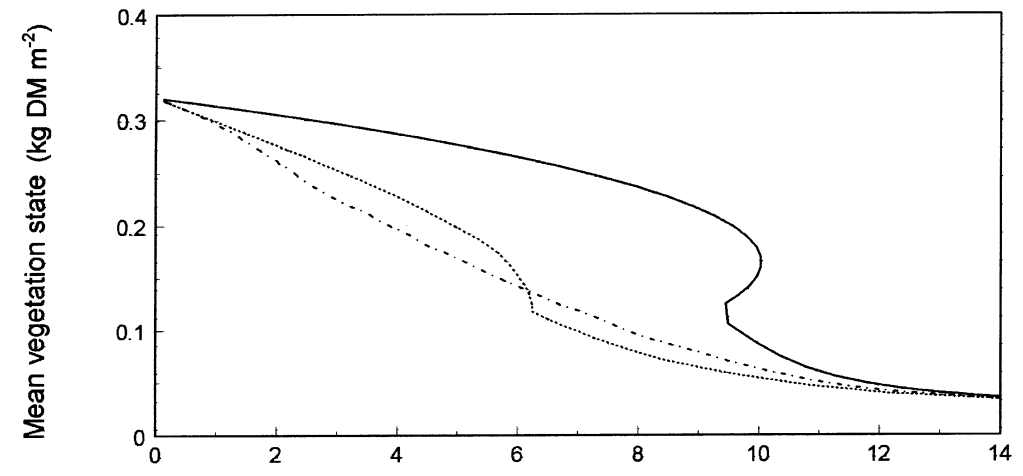

(b)

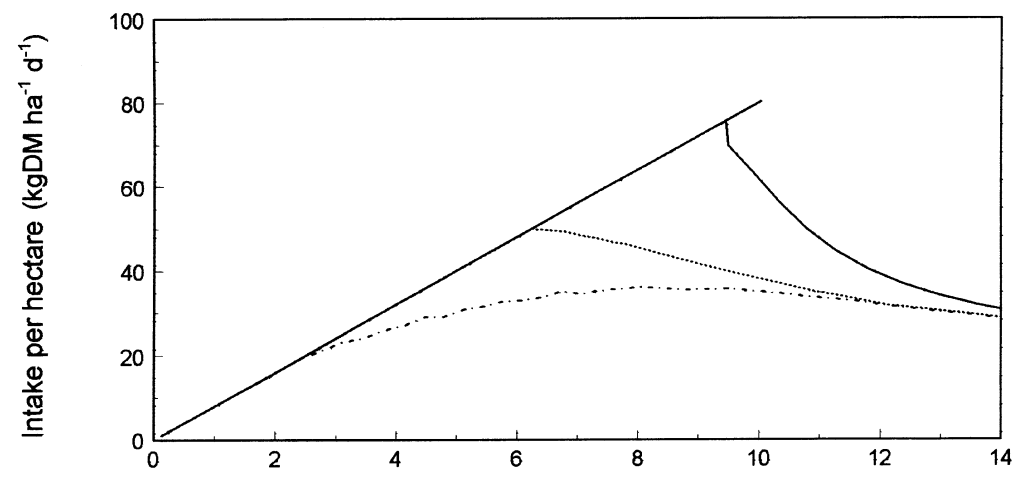

(c)

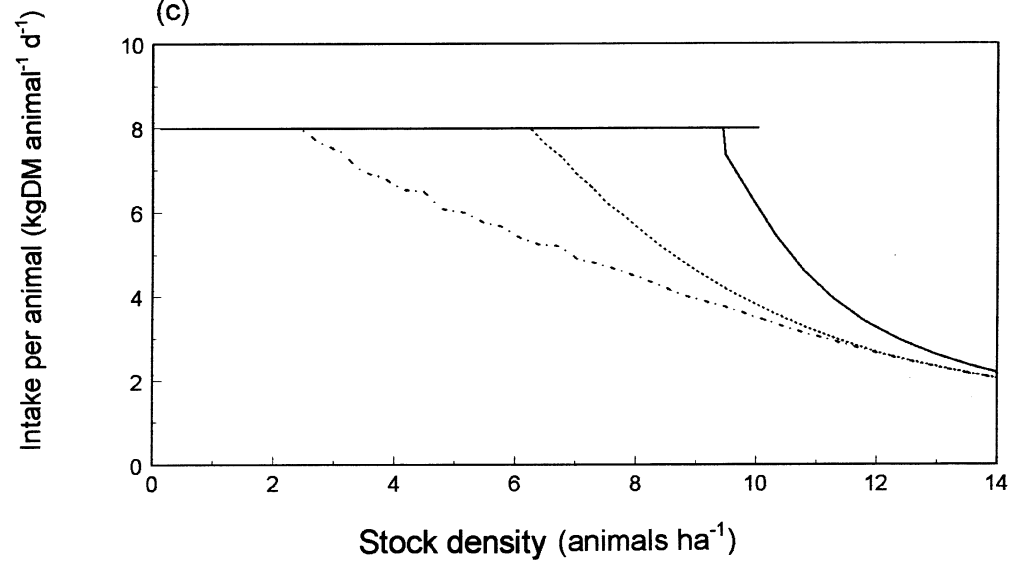

Figure 7 Differences in predictions between what is proposed as a conventional approach (solid line: non-spatial model, logistic growth function, ' $f$ ' $=0.5$ ) with a spatial approach (dotted line: new growth function, ' $f$ ' $=0.5$ ), and the further differences that arise from selective grazing (dot-dash line: partial rejection of tall patches) which can only be considered using spatial models.

equilibrium states of pastures (Schwinning and Parsons, 1999). However, modelling just twenty to fifty categories of patch state (I.R. Johnson, personal communication), each regrowing using a physiological model or modified function as proposed here, provides a close approximation to a full spatial analysis with respect to the yield of the grazing system; it illustrates appropriate heterogeneity in the frequency distributions of patch states, and still provides the opportunity to explore the impact on growth and utilization of patch selection by animals. This iteration is well within the capability of day-to-day computers and suggests how the essence of a detailed spatial analysis could be incorporated into a practical DSS model. 
In theory, it should be possible to model the grazing system on the basis of the fate of a single representative patch, but this is possible only if the appropriate 'scaling rules' are known and remain fixed. For example, if intake is calculated from bite mass, it is possible also to calculate the number of bites taken by all the animals and what this represents as a proportion of the total available area (e.g. some 5\%). Hence each day some $5 \%$ of all patches can be modelled as being defoliated to the correct residual sward state (that given by ' $f$ '). The same scaling rule can be used to scale the defoliation interval, by assuming all patches regrow for the same discrete interval (here $20 \mathrm{~d}$ ). However, this makes assumptions about how animals graze, namely deterministically and always from the largest patches in the pasture (see discussion by Ungar, 1996). The implications of this approach on system dynamics are explored by Schwinning and Parsons (1999), but there is little evidence that animals graze in this way. Moreover, for systems not in a steady state, difficulties immediately arise, because if the scaling rules are not fixed, problems arise in deriving a defoliation interval for the single representative patch.

Finally, we recognize that many grazing models assume only rotational grazing. These essentially already model plant growth as a discrete process in the succession of paddocks, but problems still arise when the period of grazing is considered. Even in rotational systems the period of defoliation can be many days and the same important interactions between plants and animals that determine the degree of utilization, and so the residual state during grazing, take place. Moreover, heterogeneity in the grazing process is not easily ruled out by management and is preferably dealt with using a set of concepts and models that can be applied to all managements. Although rotational grazing is often perceived as being a means to control heterogeneity at the within paddock scale, it in itself imposes patchy exploitation of vegetation, and so marked heterogeneity, at the between 'paddock' scale. Moreover, the time cost to 'forcing' animals to 'homogenize' one paddock (intake rate declines while animals consume a dwindling vegetation), means that other paddocks in the rotation may be accumulating biomass beyond the optimal timing for harvest, thus reducing average growth rates elsewhere. In this respect, the concepts for the constraints to the utilization of patches, exposed by bite-scale spatial models (see Parsons et al., 1999), may prove valuable for identifying the constraints to optimising the utilization of paddocks. The same processes, at both scales, generate variability in residual sward state, and in defoliation interval, and can generate marked heterogeneity. Regardless of the system of management then, there is the same general problem of identifying optimal solutions for exploiting resources spatially, always with the uncertainty of variability in the timing and severity of defoliation.

The failure of animals to harvest consistently and uniformly from the available vegetation remains one of the major challenges to efficient utilization, despite substantial research in land management over many decades. To meet this challenge requires a better understanding of how different forms of spatial heterogeneity arise, how they are sustained, their impact on yield and the stability of grazing systems, and how to control (limit or eliminate) forms that are deleterious to sustainable production. Progress may depend on a developing a deeper understanding of the spatial nature of the processes involved in grazing and the function of grazed ecosystems, but this requires some awareness of the possible pitfalls of working across spatial and temporal scales.

\section{References}

Anslow R.C. (1967) Frequency of cutting and sward production. Journal of Agricultural Science, Cambridge, 68, 377-384.

Birch C.P.D. (1999) A new generalized logistic sigmoid growth equation compared with the Richards growth equation. Annals of Botany, 83, 713-723.

Brougham R.W. (1956) Effect of intensity of defoliation on regrowth of pasture. Australian Journal of Agricultural Research, 7, 377-387.

Brougham R.W. and Glenday A.C. (1967) Pasture growth rate studies in relation to grazing management: a re-interpretation of published data. Journal of the British Grassland Society, 22, 100-107.

Brown B.J. and Allen T.F.H. (1989) The importance of scale in evaluating herbivory impacts. Oikos, 54, 189-194.

CACHо O.J. (1993) A practical equation for pasture growth under grazing. Grass and Forage Science, 48, 387-394.

CHARnov E.L. (1976) Optimal foraging, the marginal value theorem. Theoretical Population Biology, 9, 129-136.

Clark D.A., Chapman D.F., LAND C.A. and Dymock N. (1984) Defoliation of Lolium perenne and Agrostis spp. tillers, and Trifolium repens stolons in set-stocked and rotationally grazed hill pastures. New Zealand Journal of Agricultural Research, 27, 289-301.

Coughenour M.B. (1991) Spatial components of plantherbivore interactions in pastoral, ranching, and native ungulate ecosystems. Journal of Range Management, 44, 530-542.

Demment M.W., Laca E.A. and Greenwood G.B. (1987) Intake in grazing ruminants: a conceptual framework. In: Owens F.N. (ed.) Feed Intake by Cattle. Symposium Proceedings, Agricultural Experimental Station, Oklahoma State University. pp. 208-225.

EDWARDS G.R.E. (1994) The creation and maintenance of spatial heterogeneity in plant communities: the role of plantanimal interactions. PhD thesis. University of Oxford, UK. 
Edwards G.R., Parsons A.J., Penning P.D. and NewMAN J.A. (1996) Relationship between vegetation state and bite dimensions of sheep grazing contrasting plant species and its implications for intake rate and diet selection. Grass and Forage Science, 50, 378-388.

Gib B M.J., BAKer R.D. and SAyer A.M.E. (1989) The impact of grazing severity on perennial ryegrass/white clover swards stocked continuously with beef cattle. Grass and Forage Science, 44, 315-328.

Gibi M.J., Huckle C.A., Nuthall R. and Rook A.J. (1997) Effect of sward surface height on intake and grazing behaviour by lactating Holstein Friesian cows. Grass and Forage Science, 52, 309-321.

GRUNBAUM D. (1998) Using spatially explicit models to characterise foraging performance in heterogeneous landscapes. American Naturalist, 151, 97-115.

Hodgson J. and Ollerenshaw J.H. (1969) The frequency and severity of defoliation of individual tillers in set-stocked swards. Journal of the British Grassland Society, 24, 226-234.

Illius A.W. and Gordon I.J. (1987) The allometry of food intake in grazing ruminants. Journal of Animal Ecology, 56, 989-999.

Johnson I.R. and PARsons A.J. (1985) A theoretical analysis of grass growth under grazing. Journal of Theoretical Biology, 112, 345-367.

Laca E.A. and Demment M.W. (1991) Herbivory: the dilemma of foraging in a spatially heterogeneous food environment. In: Palo T. and Robbins C. (eds) Plant Defences Against Mammalian Herbivory. pp. 30-44. Boca Raton, FL: CRC Press.

Laca E.A. and Demment M.W. (1996) Foraging Strategies of Grazing Animals. In: Hodgson J. and Illius A.W. (eds) The Ecology and Management of Grazing Systems. pp. 137158. Wallingford, UK: CAB International.

LACA E.A. and OrtegA I.M. (1995) Integrating foraging mechanisms across spatial and temporal scales. Proceedings of the 5th International Rangeland Congress, Salt Lake City, Utah. July, 1995. pp. 129-132.

Laca E.A., Ungar E.D., Seligman N. and Demment M.W. (1992) Effects of sward height and bulk density on bite dimensions of cattle grazing homogeneous swards. Grass and Forage Science, 47, 91-102.

Marriott C. ANd Carrere P. (1998) Structure and dynamics of grazed vegetation. Annales Zootech, 47, 359369.

Morley F.H.W. (1968) Pasture growth curves and grazing management. Australian Journal of Experimental Agriculture and Animal Husbandry, 30, 40-45.

Morris R.M. (1969) The pattern of grazing in 'continuously' grazed swards. Journal of the British Grassland Society, 24, 65-70.

Noy-Meir I. (1975) Stability of grazing systems: an application of predator-prey graphs. Journal of Ecology, 63, 459-481.

PARsons A.J. (1988) The effect of season and management on the growth of temperate grass swards. In: Jones M.B. and Lazenby A. (eds) The Grass Crop - the Physiological Basis of Production. pp. 129-177. London: Chapman and Hall.
PARsons A.J. (1994) Exploiting resource capture - grassland. In: Monteith J.L., Scott R.K. and Unsworth M.H. (eds) Resource Capture by Crops. pp. 315-349. Nottingham: Nottingham University Press.

Parsons A.J. and Penning P.D. (1988) The effect of the duration of regrowth on photosynthesis, leaf death and the average rate of growth in a rotationally grazed sward. Grass and Forage Science, 43, 15-27.

PARsons A.J. and ChA PMAn D.F. (1998) Principles of grass growth and pasture utilisation. In: Cherney J.H. and Cherney D.J.R. (eds) Grass for Dairy Cattle. pp. 283-310. Wallingford, UK: CAB International.

Parsons A.J. and Chapman D.F. (1999) The principles of pasture growth and utilization. In: Hopkins A. (ed.) Grass: Its Production and Utilization, 3rd edn. pp. 31-89. Oxford: Blackwell Science for the British Grassland Society.

PARsons A.J., Johnson I.R. and HARvey A. (1988) Use of a model to optimise the interaction between the frequency and severity of intermittent defoliation and to provide a fundamental comparison of the continuous and intermittent defoliation of grass. Grass and Forage Science, 43, 49-59.

Parsons A.J., Thornley J.H.M., Newman J.A. and Penning P.D. (1994) A mechanistic model of some physical determinants of intake rate and diet selection in a two-species temperate grassland sward. Functional Ecology, 8, 187-204.

Parsons A.J., Carrere P. and Schwinning S. (2000) Dynamics of heterogeneity in a grazed sward. In: Lemaire G., Hodgson J., de Moraes A., de Faccio Carvalho P. and Nabinger C. (eds) Grassland Ecophysiology and Grazing Ecology. pp. 289-315. Wallingford, UK: CABI Publishing.

Penning P.D. (1986) Some effects of sward conditions on grazing behaviour and intake by sheep. In: Gudmundsson O. (ed.) Grazing Research at Northern Latitudes. pp. 219-226. New York: Plenum Publishing Corporation. Penning P.D., Parsons A.J., OrR R.J., Harvey A. and CHAMPION R.A. (1995) Intake and behaviour responses by sheep in different physiological states, when grazing monocultures of grass or white clover. Applied Animal Behaviour Science, 45, 63-78.

RICHARD S J.H. (1993) Physiology of plants recovering from defoliation. Session: Plant Growth. Proceedings of the 17th International Grassland Congress 1993, Palmerston North, New Zealand, Vol. I. pp. 85-94.

Schwinning S. and Parsons A.J. (1996a) Analysis of the coexistence mechanisms for grasses and legumes in grazing systems. Journal of Ecology, 84, 799-814.

Schwinning S. and Parsons A.J. (1996b) A spatially explicit population model of stoloniferous $\mathrm{N}$-fixing legumes in mixed pasture with grass. Journal of Ecology, 84, 815-826.

Schwinning S. and Parsons A.J. (1999) The stability of grazing systems revisited: spatial models and the role of heterogeneity. Functional Ecology, 13, 737-747.

Senft R.L., Coughenour M.B., Bailey D.W., Rittenhouse L.R., Sala O.E. and Swift D.M. (1987) Large herbivore foraging and ecological heirarchies. Bioscience, 37, 789-799. 
Silander J.A. and Pacala S.W. (1990) The application of plant population dynamic models to understanding plant competition. In: Grace J.B. and Tilman D. (eds) Perspectives on Plant Competition. pp. 67-69. New York: Academic Press.

Spalinger D.E. and Нов в S N.T. (1992) Mechanisms of foraging in mammalian herbivores: new models of functional response. American Naturalist, 140, 325-348.

Tainton N.M., Morris C.D. and Hardy M.B. (1996) Complexity and Stability in Grazing Systems. In: Hodgson J. and Illius A.W. (eds) The Ecology and Management of Grazing Systems. pp. 275-299. Wallingford, UK: CAB International.

THORNLEY J.H.M. (1999) Grassland Dynamics, an Ecosystem Simulation Model, 241 pp. Wallingford, UK: CAB International.

Thornley J.H.M. and Johnson I.R. (1990) Plant and Crop Modelling. 669 pp. Oxford: Clarendon Press.

TILman D. (1994) Competition and biodiversity in spatially structured habitats. Ecology, 75, 2-16.

UnGAR E.D. (1996) Ingestive Behaviour. In: Hodgson J. and Illius A.W. (eds) The Ecology and Management of Grazing Systems. pp. 185-218. Wallingford, UK: CAB International.
Ungar E.D. and Noy-Meir, I. (1988) Herbage intake in relation to availability and sward structure: grazing processes and optimal foraging. Journal of Applied Ecology, 25, 1045-1062.

Ungar E.D., Genizi A. and Demment M.W. (1991) Bite dimensions and herbage intake by cattle grazing short, hand-constucted swards. Agronomy Journal, 83, 973-978.

WADE M.H. (1991) Factors affecting the availability of vegetative Lolium perenne to grazing dairy cows with special reference to sward characteristics, stocking rate and grazing method. PhD thesis, University of Rennes, France.

Wiens J.A. (1989) Spatial scaling in ecology. Functional Ecology, 3, 385-397.

WoodWARD S.J.R. (1998) Dynamical systems models and their application to optimising grazing management. In: Peart M.R. and Curry R.B. (eds) Agricultural Systems Modelling and Simulation (Series: Books in Soils, Plants, and the Environment). pp. 419-473. New York: MarcelDekker.

WoodWARd S.J.R. and WAKe G.C. (1994) A differential delay model of pasture accumulation and loss in controlled grazing systems. Mathematical Biosciences, 121, 37-60. 